\title{
LOS PRIMEROS INDICIOS DE LA RECEPCIÓN DE La CONDICIÓN hUMANa de HaNNAH ARENDT
}

\section{[THE FIRST INDICATIONS OF THE RECEPTION OF HANNAH ARENDT'S THE hUMAN CONDITION]}

Beatriz Porcel

Professora Titular de Filosofía Política y de Teoría Política

Facultad de Humanidades y Artes de la Universidad Nacional de Rosario

DOI: http://dx.doi.org/10.21680/1983-2109.2018v25n48ID14172

Natal, v. 25, n. 48

Set.-Dez. 2018, p. 15-30

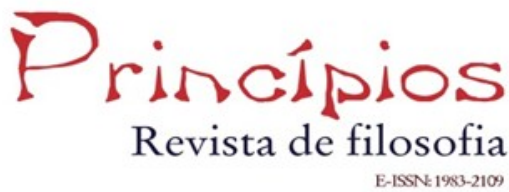


Resumen: El interés de este trabajo se dirige a presentar algunas de las varias reseñas críticas que mereció La Condición Humana -escrito por Hannah Arendt y publicado en Nueva York en 1958- durante ese año, en 1959 y en 1960, tanto en el medio académico como en el periodismo especializado. A posteriori, parece que esta obra, situada entre las importantes controversias de su antecesora Los Orígenes del Totalitarismo y su sucesora Eichman en Jerusalem, fue recibida con menos virulencia; más bien lo que suscitó fue desconcierto y algo de perplejidad. Relevamos un total de dieciocho reseñas, la mayoría aparecida en los años 1958 y 1959, y en mucho menor medida en 1960. Las publicaciones que las acogieron fueron casi todas ellas de carácter académico, en general muy conocidas y escritas por profesores e intelectuales en general también conocidos. Hemos seleccionado algunas de ellas mostrando sus claves interpretativas para finalizar delineando como hipótesis que la casi general incomprensión de la obra arendtiana se debió al estado de la ciencia y la teoría política imperante en los Estados Unidos con predominio de las posiciones positivista y conductista.

Palabras clave: Arendt; La Condición Humana; Primeras reseñas.

Abstract: The object of this work is to present some of the many critical reviews that The Human Condition - written by Hannah Arendt and published in New York in 1958 - received during that year, in 1959 and in 1960, both in the academic environment and in specialized journalism. Later on, it seems that this work, that falls between the significant controversies of its predecessor The origins of Totalitarianism and its successor Eichman in Jerusalem, was received with less animosity, generating instead bewilderment and some perplexity. We found a total of eighteen reviews, most of them published in 1958 and 1959, and in a lesser amount in 1960. The publications that contained them were mostly academic in nature and generally well-known, and written mainly by well-known professors and intellectuals. We have selected some of them, providing interpretation pointers in order to finalize the hypothesis that the almost generalized misunderstanding of the Arendtian work was due to the state of science and the prevailing political theory in the United States with a predominance of positivist and behavioral mindsets.

Keywords: Arendt; The Human Condition; First Reviews. 
Como sabemos, La Condición Humana de Hannah Arendt apareció en Nueva York en 1958. El interés de este trabajo se dirige a presentar algunas de las varias reseñas críticas que el libro mereció durante ese año, en 1959 y en 1960, tanto en el medio académico como en el periodismo especializado. En 1958, además, se publica la segunda edición de Los Orígenes del Totalitarismo en la versión que conocemos, es decir, con el añadido del fundamental capítulo "Ideología y Terror" que Arendt escribe junto con La Condición Humana. A posteriori, parece que esta obra, situada entre las importantes controversias de su antecesora Los orígenes del totalitarismo y su sucesora Eichman en Jerusalem, fue recibida con menos virulencia; más bien lo que suscitó fue desconcierto y algo de perplejidad.

Relevamos un total de dieciocho reseñas, la mayoría aparecida en los años 1958 y 1959, y en mucho menor medida en 1960. Las publicaciones que las acogieron fueron casi todas ellas de carácter académico y en general muy conocidas, como The Review of Politics, Commentary, American Anthropologist, American Quarterly, American Political Science Review, Partisan Review, entre otras, y escritas por profesores e intelectuales en general también conocidos. La selección que elegimos para este trabajo es la siguiente: en primer lugar, en 'Una autora de élite' mostramos un análisis que da como resultado la crítica más negativa; en segundo lugar, en 'Un libro escrito para mí' la reseña que —en el extremo opuesto- es un delicado elogio y una amorosa lectura; y por último, en 'Un libro extraño', un repertorio de tres notas comunes seleccionadas de un grupo más homogéneo. Se trata, como adelantamos, de recepciones que juzgan La Condición Humana de maneras entre desconcertadas, enceguecidas y ofuscadas, que realizan excursiones en el campo sin fronteras de la letra del texto fundador y nos resultan hoy tan desplazadas de nuestras referencias. Numerosas preguntas surgen de esta pequeña investigación. ¿El contexto definirá siempre los modos de leer? ¿Es posible hablar de una política de la lectura? ¿De qué manera se lee el sentido de 
un texto cuando aparece referido en una revista académica, cuando es leído por los grandes aparatos amplificadores de las editoriales que comienzan a fijar el canon? Esos primeros análisis ¿crean protocolos de lecturas que durante un tiempo fijan el sentido del texto? Trayectoria escrituraria, ejercicios sobre un pensamiento inmigrante, saberes y críticas a contrapelo. Cada gran texto como este que nos ocupa ¿habitará siempre en la brecha del 'ya no, todavía no'? El interés de este trabajo consiste, por lo tanto, en advertir la distancia que separa nuestra celebración de los méritos de La Condición Humana con aquellos iniciales receptores.

\section{Una autora de élite}

¿Por qué tantos críticos consideran este libro brillante en lugar de decir que es arrogante? Lincoln Reis —en su reseña aparecida en la revista Commentary en junio de 1959- encuentra que La condición humana es solamente una nueva versión de la clásica apología de una élite y que la racionalización de los prejuicios entendidos como parcialidad — se eleva a teoría de la historia ${ }^{1}$.

1 Esta reseña está ampliamente comentada en la correspondencia ArendtMcCarthy. El 28 de junio de 1959, McCarthy la describe como otro ataque vicioso, comentándole a Arendt que Lincoln Reis, colega suyo en el Bard College y protagonista de su novela The Groves of Academe, es un personaje que puede caracterizarse por su "titilante malignidad y por su insensibilidad evidente", sin convicciones políticas, un acomodaticio que -además- la odia. McCarthy cree que tanta maldad en el comentario crítico tiene que haber sido contratada, al estilo de un gánster a sueldo. Se lamenta por la desaparición de una antigua ética que impedía que alguien atacara por escrito a una persona con la que tenía cuestiones personales, ya que primaba el gesto liberal de la imparcialidad al presentar una reseña. Las "cuestiones personales" aquí referidas son las que Arendt tuvo con la revista Commentary, que en 1957 no aprobó y por lo tanto no publicó un artículo suyo sobre las nuevas leyes de derechos civiles, previamente encargado por la editorial. Terminó siendo "Reflexiones sobre Little Rock" aparecido en Dissent en 1959 (Brightman, 1999, p. 84 et seq.). 
¿Cuáles son los puntos centrales de la crítica de Reis a $L a$ condición humana, y a qué conclusiones arriba?

Primero, aquello que podría señalarse como cuestiones metodológicas junto con cuestiones de estilo: Reis sostiene que las definiciones que Arendt presenta son solamente recursos retóricos de los cuales no proceden argumentos válidos porque el método de análisis utilizado no es lógico, sino que se trata de una especie de serie de asociaciones cuyas reverberaciones sonoras se confunden con el significado. Según Reis, La condición humana se apoya en un artificio de ingenio muy grande - "aparato formidable" lo llama- que configura un espectáculo de erudición y pompa que Arendt toma prestado para sostener una tesis frágil: en esencia, el libro es otra versión de la clásica apología de una élite. Cuando Reis menciona "aparato formidable" y "tomar prestado", se refiere al elenco que la autora pone a su servicio formado por Marx, los Padres de la Iglesia, Platón, Aristóteles, Locke, la Biblia y Adam Smith, autoridades intelectuales a las que añade autoridades menores en mil notas al pie que tienen la misión de dar la reconfortante seguridad de lo familiar y conocido. Reis objeta el uso de estas relaciones que para Arendt son como un látigo con el que los mantiene a raya en su argumento, y cuando esto no es posible, los refuta. Por lo tanto, el texto - desde esta perspectivaaparece como un dispositivo de brillo retórico, de enredos verbales, sin originalidad, y con la marca de elitismo y arrogancia que más abajo retomará.

Segundo, con respecto al análisis de las categorías importantes como "labor, trabajo y acción", Reis considera difícil saber cómo procede el argumento, si labor, trabajo y acción están destinados a ser etapas históricas en el desarrollo del hombre o categorías lógicas. Reis cree que Arendt, a la manera hegeliana, los trata de manera intercambiable — nunca claramente separables —, y el hecho de recurrir a "etiquetas generales" como "labor" y "trabajo" le hace posible construir un número de plausibles esquemas descriptivos, aunque en última instancia resultan vacuos, abstra- 
cciones que nunca pueden resumir o abarcar la vida humana por completo. Reis apela al uso del sarcasmo para desacreditar estas distinciones (por ejemplo, se pregunta si trabajar en un periódico es labor o trabajo, ya que el resultado es un producto perecedero; también manipula deliberadamente lo natural que se transforma en el trabajo: ¿debemos decir que la piedra en una estatua de mármol ya no es la piedra o es menos piedra?). Dice Reis que el tratamiento de la "acción" es aún más confuso. "Acción" se identifica con el sentido especial de que la persona sea un individuo y haga su propia historia, pero también "acción" se vincula con las relaciones entre las personas. ¿De qué manera pregunta- ambos sentidos van de la mano y qué tienen en común? También observa críticamente la posición arendtiana que sostiene que las acciones comienzan pero no tienen un fin previsible. Reis, aunque concede que las consecuencias no pueden preverse y que la acción puede continuar indefinidamente, cree que esto no significa que las acciones no tengan las consecuencias que pretendemos, o que somos necesariamente culpables por las consecuencias no deseadas de las acciones. Según Reis, Arendt avanza en el ámbito de la sociedad y del gobierno estableciendo lo que el crítico considera que son vínculos o puentes inciertos, al sostener que la vida de acción (de la cual la vida política griega fue el ejemplo histórico más puro) necesita ser reavivada y fortalecida.

El tercer punto que nos interesa mostrar es el rechazo por parte de Reis de la posición de Arendt con respecto a la ciencia y la técnica modernas: cree que rechazar la tecnología con criterios morales es tan inútil como culpar a Prometeo por haber introducido el fuego, una posición que es presentada como una respuesta emocional y sin embargo revelada como una verdad, otra más en torno a las discusiones contemporáneas sobre el hombre y su lugar en el mundo, resultado de un rechazo de ese mundo.

Las conclusiones a las que arriba Reis después de tantas invectivas mantienen el tono de ataque vicioso, como dice McCarthy. Sitúa el texto en lo que llama "pesimismo cultural", una posición 
institucionalizada en el pensamiento contemporáneo que es además reaccionaria, intolerante y doctrinaria, snob y pseudo-libresca. Para la figura de Arendt, Reis agrega algo más: su estilo germanopontificio, tan cómico como los personajes de las preciosas ridículas de Moliére, su desprecio por el hombre-masa, su nostalgia por el pasado de oro griego; en resumen, ni arriesgado, ni poco convencional, ni nuevo. "Arendt nos da un suplemento de domingo de apocalipsis; ¿persistirán sus temblores más allá del desayuno?”.

\section{"Un libro escrito para mí"}

El poeta Auden se hace cargo de la reseña de La condición humana de su gran amiga Hannah Arendt en idéntica fecha que la de Reis, junio de 1959. Aparece en Encounter ${ }^{2}$ y lleva el título de "Pensar en lo que hacemos". ¿Se trata, dado el carácter del vínculo entre ambos, de un texto teñido de parcialidad, como el de Reis pero en sentido contrario? Posiblemente sí, aunque podríamos responder que no, si nos posicionamos en la capacidad interpretativa de cada lectura, es decir: Reis ataca La condición humana porque este fue el objetivo, pero además ataca La condición humana porque no comprendió la perspectiva teórica. Y Auden elogia La condición humana porque estima a la autora, pero además porque comprendió la obra.

${ }^{2}$ Auden, 1959, p.72-76. Encounter fue una revista político-literaria publicada en el Reino Unido, fundada en 1953 por el poeta Stephen Spender y el periodista Irving Kristol, cerrada en 1991. Fue una revista intelectual y cultural anglo-americana, originalmente asociada con la izquierda anti-estalinista. La revista recibió financiación encubierta de la CIA con la intención de contrarrestar la idea de la neutralidad en la guerra fría y raramente fue crítica de la política exterior de EE.UU. Los editores tuvieron una considerable libertad editorial. Spender se desempeñó como editor literario hasta 1967, cuando se reveló la financiación mencionada. Thomas W. Braden, quien dirigió las operaciones de la División de Organizaciones Internacionales de la CIA entre 1951 a 1954, declaró que el dinero para la revista procedía de la CIA, y que pocos fuera de la CIA lo sabían. Además había sido colocado un agente en una organización de intelectuales con sede en Europa llamado el Congreso por la Libertad Cultural. La publicación cesó —como mencionamos—en 1991. 
Auden considera que La condición humana pertenece a esa clase selecta de libros que cuando se los lee se siente que ha sido escrito para uno, para responder a las preguntas que uno siempre se ha hecho. Que la felicidad de su lectura produce el deseo de compartirlo al mismo tiempo que se lo quiere poseer celosamente propio.

En un mundo en riesgo de destrucción, Arendt - dice Audensimplemente nos pide que pensemos en lo que estamos haciendo, evitando ofrecer presuntuosas recetas salvíficas. La determinación de pensar en lo que estamos haciendo, para Arendt, va de la mano con un acuerdo sobre el significado de las palabras, que a su vez requiere que nos demos cuenta de lo que estas palabras han significado en el pasado. No sería inexacto, cree Auden, llamar a La condición humana un ensayo de etimología, un nuevo examen de lo que pensamos y lo que queremos decir, lo que realmente significamos cuando usamos palabras como naturaleza, mundo, labor, trabajo, acción, privado, público, social, político, etc. Por lo tanto, la reseña presenta algunas definiciones como si fuera un diccionario, eligiendo Naturaleza, Mundo, Acción, y en cada una de ellas despliega el arsenal teórico arendtiano. En 'Naturaleza', Auden dilucida el entramado del hombre como organismo biológico para poder explicar la labor y la configuración del animal laborans; en 'Mundo', se ocupa del hombre que trabaja y que fabrica a fin de transcender el ciclo natural y la muerte, configurando así un mundo de cosas perdurables que permita "sentirse en casa". Por último, en "Acción", muestra la aparición de seres únicos que requieren de un espacio público para decir quiénes son y que definen su libertad en su ilimitada capacidad de acción. En este apartado de la reseña, Auden se permite explicar muy claramente los límites que representan la ley, el perdón y la promesa, y establece la recuperación de "lo griego" por parte de Arendt, la distinción entre público y privado, luego la emergencia moderna de lo social y las transformaciones operadas en el mundo contemporáneo con la aparición de la técnica. Auden se cuida de ofrecer 
citas del texto y no evita afirmaciones, como por ejemplo, que "la definición de Arendt del poder político, a diferencia de la violencia o la fuerza, es admirable", para concluir con la confianza en haber dado una ligera idea de la riqueza y fascinación de La condición humana.

\section{Un libro extraño}

Robert Bierstedt (1959), en American Sociological Review, comenta La condición humana señalando las anfractuosidades del pensamiento de la autora, difíciles de seguir, y presume que el lector puede perder la confianza en su capacidad para comprender qué es lo que Arendt está tratando de decir. Para Bierstedt también es complicado discernir fácilmente la perspectiva disciplinar en la que incluir el libro, crítica similar - recordemos - a los problemas de los reseñadores de Los Orígenes del Totalitarismo: "No es filosofía en el sentido habitual, no es teoría económica o sociología política en el sentido ortodoxo, si hay un ámbito de pertenencia como mejor puede caracterizarse sería como un tratado de economía filosófica". La distinción arendtiana entre labor, trabajo y acción desarrolla argumentos en un nivel que para el comentarista es a la vez erudito y profundo, complejo y oscuro. A diferencia de otros análisis, el de Bierstedt destaca la interpretación más política que metafísica que Arendt da del mito platónico de la caverna, del zoon politikon de Aristóteles, del punto de Arquímedes, y de la duda cartesiana como ejemplos de temas ingeniosos y apasionantes, sin que estas altas calificaciones sean incondicionales: la autora - se nos dice- muchas veces sacrifica coherencia por originalidad y lleva algunas de sus interpretaciones demasiado lejos para sostener la credibilidad. A pesar de la confusión expuesta, el comentarista define La condición humana como una importante contribución a la historia intelectual de nuestro tiempo.

Para Charles Frankel (1959), en la reseña aparecida en Political Science Quarterly, el problema se presenta con la conceptualización 
de Arendt de labor, trabajo y acción, afirmando que no es nada claro si se refiere a tres tipos distintos de actividades (como la autora en general parece sugerir) o a tres elementos que se pueden encontrar, al menos potencialmente, en cualquier actividad. Frankel cree que los argumentos morales de Arendt se ven malogrados por una tendencia a declarar sus - a veces bastante extrañas - preferencias personales como si fueran verdades psicológicas universales. Concluye que La condición humana, a pesar de sus oscuridades, es un comentario mordaz sobre los aspectos morales olvidados de la labor y el trabajo en la sociedad contemporánea. Sin embargo, aunque la autora nos pide que aceptemos toda una teoría de la cultura moderna, esta posición se basa en principios que para el reseñador son indefinidos e indefendibles.

John Bennet, en American Anthropologist, escribe un largo análisis de La condición humana, a la que, fundamentalmente, le reclama tres cosas: que, si bien la presentación de Arendt de sus categorías y conceptos - labor, trabajo, acción, público, privadoda la apariencia de precisión, después de un examen cuidadoso esas distinciones se disuelven en borrones. ¿Cómo se puede realmente decir si una actividad humana real en particular pertenece a la labor o al trabajo? Sus conceptos ¿se refieren a concepciones ideológicas o a las actividades reales? Para Bennet también hay imprecisión en el uso que de estos conceptos lleva adelante Arendt a lo largo de la historia de las ideas y al examinar la etimología de labor, trabajo y acción en las lenguas europeas para demostrar la validez e importancia en los asuntos humanos. Bennet se pregunta quién ha determinado que estos tres conceptos son básicos y esenciales: ¿Arendt, los filósofos griegos, los analistas sociales, los hablantes de lenguas europeas? Arendt podría haber recurrido a los aportes de la antropología, de la historia biológica y cultural, en lugar de quedarse en el reino de la idea y la semántica.

A este primer señalamiento de la insuficiencia de los aportes de otras disciplinas, Bennet suma el de la limitación del marco 
cultural o civilizatorio, ya que Arendt no trata con las culturas no occidentales y no reconoce la variabilidad cultural. Arendt se refiere a "la condición humana", y todo el libro — dice Bennetestá escrito con un estado de ánimo de generalidad olímpica, ya que es enteramente una obra sobre la civilización occidental, del resto del mundo no hay evidencia, y todo el complejo patrón de la civilización oriental se ignora. Le cabe la sospecha que, sin ser consciente de ello, Arendt se mueve en la ambivalencia etnocéntrica del hombre occidental moderno: por un lado, Occidente es la única civilización de la realización humana, pero por el otro Occidente ha tomado la dirección equivocada y pone en peligro a la humanidad en su conjunto.

Por último, Bennet indica otra objeción antropológica: Arendt (como fenomenóloga) parece no reconocer ningún cambio evolutivo en el hombre; solamente analiza la inversión de la jerarquía de la vita activa en las civilizaciones mediterráneas, y así se conceptualizan todas las revoluciones tecnológicas, los cambios en la estructura social, y las alteraciones en los poderes intelectuales del hombre de los últimos 2000 años, pero en ninguna parte del texto se reconoce que el desarrollo de la tecnología representa una expansión continua de las capacidades humanas. El uso de aparatos humanos, culturales, materiales o de otro modo, para la construcción de un mundo humano más elaborado y un dominio de la naturaleza le parece a Arendt, según Bennet, una cosa peligrosa: ha llevado a la deshumanización del hombre pero nunca se complementa con los logros del hombre. El pesimismo que subyace en la perspectiva de Arendt no da ninguna salida, no hay manera de guiar el mundo. Bennet no critica la crítica, indicando que la obra de Arendt tiene el gran mérito de llamar nuestra atención sobre muchas carencias espirituales y problemas sociales, pero el comentarista cree que se necesita algo más: un punto de vista constructivo, basado en el reconocimiento de la evolución del hombre. La conclusión de esta reseña es que La condición humana es un libro brillante, importante y muy difícil, que contiene gran 
parte de observaciones con la que cualquier analista serio de la sociedad y la cultura moderna debe estar de acuerdo, pero también contiene actitudes y giros de razonamiento basados en evaluaciones particulares que requieren serias críticas.

\section{Conclusión}

Estas lecturas, la mayoría de las cuales exhibe un tono de desconcierto y extrañeza, se encuentran en relación con el medio académico en el que se desarrollaba la teoría política en Estados Unidos durante la década de 1950. Desde unos años antes, los especialistas de la política creían no haber alcanzado el ideal científico esperado, uno de cuyos principios centrales, propuesto por conductistas como Easton, era el desarrollo de una ciencia política organizada por la metodología de las ciencias naturales. El conductismo imperante en ese momento daba prioridad a la idea de la ciencia pura, modificando los programas de investigación en ciencia política a través de la incorporación de métodos cuantitativos y sistemáticos de análisis y celebrando el avance de la teoría empírica como clave del progreso científico (Gunnell, 1991, p. 642 et seq.).

Las siguientes discusiones se dedicaron a polemizar acerca del objeto y los alcances de la ciencia política, de la historia de la teoría política, y el carácter normativo o empírico de la teoría política. Un nuevo problema se hace presente en la década de 1940 con la irrupción de las ideas propagadas por los emigrados alemanes: Strauss, la propia Arendt, Adorno, Voegelin, Neuman, Marcuse y Horkheimer, entre otros, quienes influyeron significativamente en el subcampo de la teoría política. Algunos de ellos, como Arendt, Strauss, Voegelin y Marcuse, sostenían la idea de que la historia de la política y la teoría política en Occidente, al menos en los últimos tiempos, estaba declinando, idea asociada a la crítica al liberalismo y a la ciencia y la técnica, sin ignorar las diferentes perspectivas críticas y políticas de cada uno. El liberalismo fue entendido como el hilo que tramó el fascismo y el 
nazismo, la fachada de fuerzas sociales represivas, igual que la ciencia y la tecnología fueron presentadas bajo un aspecto de instrumentos de opresión y enemigas del humanismo.

De diferente tenor fue el lamento de David Easton sobre el fin de la teoría política y la necesidad de su reconstrucción (Easton, 1953). El argumento de Easton sostenía que la tradición comenzada con los griegos había experimentado un empobrecimiento de la mano de los teóricos. Es fácil entonces comprender cómo la llamada filosofía o teoría política "especulativa" tuvo dificultades para abrirse paso en una cosmovisión pragmatista y realista. Casi sin excepción Hannah Arendt y los demás emigrados buscaron, ya sea en la historia o al costado de ella, la fuente para un juicio crítico sobre la modernidad y sobre la política misma, gesto teórico que les valió el pasar a ser antagonistas de la perspectiva de la ciencia política americana. Ante esto, la crítica conductista cristalizó y avivó actitudes hostiles y voces adversas causando divisiones en el campo disciplinar.

Ante La Condición Humana de Arendt, la sorpresa de las primeras referencias se traduce en una variedad de apropiaciones críticas y de efectos de lectura: virulencia, rigidez y severidad. La mayoría de las veces, perplejidad ante el análisis, incapacidad para reconocer una metodología renovada y dificultad para encuadrar disciplinariamente el texto, críticas que por otra parte ya había merecido el anterior Los Orígenes del Totalitarismo. La propuesta arendtiana de la distinción fenomenológica entre labor, trabajo y acción resuena original y al mismo tiempo impropia; la impugnación a la modernidad que recorre el texto, si bien es aceptada en parte, aparece como un exceso crítico, como apocalíptica, como pars destruens a la que le falta la pars construens. Argumentos calificados de indefinidos o vagos son al mismo tiempo juzgados como insostenibles, despojando a la obra de Arendt de toda sutileza analítica, enviándola al brumoso lugar de libros extraños. Sesenta años después, estamos celebrando la potencia teórica de La Condición Humana, valorándola como uno de los textos im- 
prescindibles de la filosofía política contemporánea, y —de manera invertida-como lecturas desviadas aquellas primeras reseñas.

\section{Bibliografía}

ADAMS, Robert Martin. Review Man and Nothing: Earthbound Comments The Human Condition by Hannah Arendt; Irrational Man by William Barrett; Nature, Man, and Woman by Alan W. Watts. The Hudson Review. v. 11, n. 4, Winter 1958-1959, p. 626-631.

AUDEN, W. H. Thinking What We Are Doing. Encounter. n. 12, June 1959, p. 72-76.

BALL, Terence. Aonde vai a Teoría Política?. Revista de Sociología e Política. Curitiba, n. 23, nov. 2004, p. 9-22.

BENNETT, John. Review The Human Condition, Hannah Arendt. American Anthropologist. n. 61, 1959, p. 684-688.

BIERSTEDT, Robert. Review The Human Condition. American Sociological Review. n. 24, 1959, p. 113-114.

BRIGHTMAN, Carol. (Ed.). Between Friends: The Correspondence of Hannah Arendt and Mary McCarthy, 1949-1975. New York: Harcourt Brace, 1999.

BOULDING, Kenneth. Review Philosophy, Behavioral Science, and the Nature of Man. World Politics. v. 12, n. 2, Jan. 1960, p. 272-279.

CARMICHAEL, Leonard. Review The Human Condition by Hannah Arendt. Technology and Culture. v. 1, n. 2, Spring 1960, p. 177-178.

COOK, Thomas. Review The Human Condition, by Hannah Arendt. The American Political Science Review. v. 54, n. 2, June 1960, p. 518. 
CRICK, Bernard. The American Science of Politics: Its Origins and Conditions. New York: Taylor \& Francis e-Library. 2001. (1959).

CROPSEY, Joseph. Review Hannah Arendt The Human Condition. Social Research. v. 26, n. 1, Spring 1959, p. 121-124.

DENSBERGER, Kathryn. A History of the Reception of the Work of Hannah Arendt \& Why It's So Popular Now. (Paper presented at the annual meeting of the American Sociological Association Annual Meeting. Sheraton Boston and the Boston Marriott Copley Place, Boston, MA, July 31, 2008). Disponible en:

$<$ http://citation.allacademic.com//meta/p_mla_apa_research_citation/2 /4/2/7/6/pages242764/p242764-2.php>. Consultado en: 1 Ā̄br. 2018.

DONOGHUE, Denis. Review After Reading Hannah Arendt. Poetry. v. 100, n. 2, British Number May 1962, p. 127-130.

EASTON, D. The Political System: An Inquiry into the State of Political Science. New York: A. A. Knopf, 1953.

FRANKEL, Charles. Review The Human Condition. Political Science Quarterly. v. 74, n. 3, Sep. 1959, p. 420-422.

GUNNELL, John. Philosophy and Political Theory. Government and Opposition. Cambridge, v. 14, n. 2, April 1979, p. 198-216.

GUNNELL, J.; EASTON, D.; and GRAZIANO, L. The Development of Political Science: A Comparative Survey. London: Routledge, 1991.

LEATHERNAB, LeRoy. Review: Homage to the Secret-Bearer. The Sewanee Review. v. 72, n. 2, Spring 1964, p. 329-334.

MERRELL LYND, Helen. Review The Human Condition by Hannah Arendt. The American Scholar. v. 28, n. 1, Winter 1958-59, p. 108-110.

MEYER, Heinrich. Review The Human Condition by Hannah Arendt. Books Abroad. v. 33, n. 1, Winter 1959, p. 29. 
PETERS, Richard. Dark Illumination. The Nation. Oct. 4th 1958, p. 196197.

REIS, Lincoln. Sunday - Supplement Apocalypse. Commentary, 27, June 1959, p. 541.

WARD, John William. The Inside of History Reviews. American Quarterly. v. 11, n. 2, Part 1, Summer 1959, p. 184-189.

WEISSKOPF, Walter A. Review The Human Condition by Hannah Arendt. Journal of Political Economy. v. 68, n. 4, Aug. 1960, p. 420-421.

Artigo recebido em 2/05/2018, aprovado em 22/05/2018 